\title{
IMPACT OF THE COOLING EQUIPMENT ON THE KEY DESIGN PARAMETERS OF A CORE-FORM POWER TRANSFORMER
}

\author{
Tamás Orosz — Zoltán Ádám Tamus
}

\begin{abstract}
The first step in the transformer design process is to find the active part's key design parameters. This is a non-linear mathematical optimisation task, which becomes more complex if the economic conditions are considered by the capitalisation of the losses. Geometric programming combined with the method of branch and bound can be an effective and accurate tool for this task even in the case of core-form power transformers, when formulating the short-circuit impedance in the required form is problematic. Most of the preliminary design methods consider only the active part of the transformer and the capitalised costs in order to determine the optimal key design parameters. In this paper, an extension of this meta-heuristic transformer optimisation model, which takes the cost of the insulating oil and the cooling equipment into consideration, is presented. Moreover, the impact of the new variables on the optimal key design parameters of a transformer design is examined and compared with the previous algorithm in two different economic scenarios. Significant difference can be found between the optimal set of key-design parameters if these new factors are considered.

Keywords: design optimization, mathematical programming, power transformers, transformer insulation, oilinsulated transformer
\end{abstract}

\section{INTRODUCTION}

The design process of the power transformer is a complex, multidisciplinary optimisation task. The specified parameters must be fulfilled not only electrically, but also mechanically and thermally. Consequently, transformer design optimisation belongs to the most general category of mathematical optimisation problems. In this field, there are no algorithms or iteration schemes, which guarantee the finding of the global optimum [1-3]. Moreover, the transformer's cost optimisation process is based not only on the manufacturing cost minimisation, but the minimisation of the total cost of ownership(TCO). This idea is not new, first mentioned by Kapp [4], and shortly before WW1, the pioneer company in transformer manufacturing (GANZ) considered the lifetime costs. They produced transformers with different core loss and load loss ratios for water and steam power plants $[5,6]$. Nowadays, more sophisticated methods are used considering many more economic parameters than the utilization factor of the equipment alone. The technique of capitalisation of the losses is used generally to take the economic aspects into consideration [7]. Because of the complexity and a lot of uncertainty in this task, several theories have been proposed to explain the capitalisation factors in the literature [8-23].

From the beginning of the 1950's many computer based algorithms have been introduced to determine the optimal key design parameters simplifying and accelerating the time-honoured, cut-and-try based design process [2,13-18]. Therefore in the last decades, a wide range of mathematical optimisation methods have been implemented for this design optimisation problem, such as
Monte Carlo simulation [18], artificial intelligence techniques and neural networks [19], evolutionary and genetic algorithms [13-18], and geometric programming (GP) $[1,20,24,25]$. The importance of GP is based on the recent developments in the solution methods, which can solve even large-scale GPs extremely efficiently and accurately [26-28]. The authors have shown a general metaheuristic approach, which is based on the GP and capable to determine any core-form power transformer designs [25]. All of the reviewed methods [14], including the previously mentioned meta-heuristic optimisation method [25], are focused on the design of the active part of the transformer, which consists of the manufacturing price of the core and the windings, only. These models have a satisfactory level of accuracy in the absolute value of the TCO, hence these papers do not deal with the cost of the insulation oil and the radiator banks in the case of coreform power transformers. There are two main reasons, why this simplification cannot cause significant difference in the value of the global optima: well known, that the shape of the optimal curve is flat, secondly the relative value of the cooling equipment is only $5-15 \%$ of the product price and the cost of this equipment is assumed as a linear function of the losses [2]. Instead of the low price of a radiator bank the radial size of this equipment has a huge impact on the overall size of a transformer which can be restrictive in the case of strict size limitations. Moreover, the main goal of this optimisation task to provide the initial values of the key design parameter not only to predict the optimal value of the TCO.

Moreover, there are new insulating oils, synthetic esters and silicon oils on the market with different thermal and electrical performance which are not consid-

* Department of Electrical Power Engineering, Budapest University of Technology and Economics, Egry J. u. 18, Budapest, Hungary, orosz.tamas@vet.bme.hu 
Table 1. Basic set of design variables in the realized optimisation model

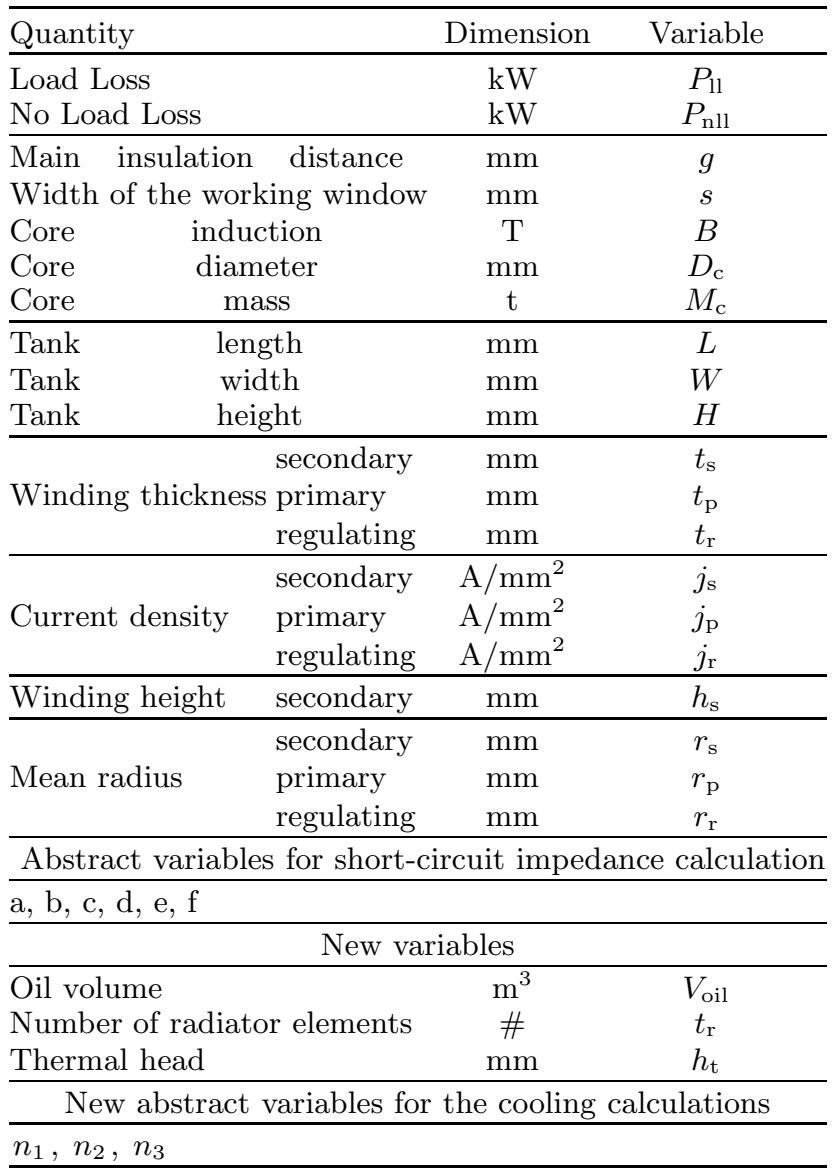

ered in these preliminary design optimisation algorithms [29]. This paper begins with a short introduction of the preliminary introduced meta-heuristic approach. Then it presents an extension for this meta-heuristic algorithm, which can take the insulation oil into consideration. Finally, the results of the new, extended transformer optimisation algorithm are analysed and compared by the previous one in a case study with two economic scenarios.

\section{THE GEOMETRIC PROGRAMMING BASED META-HEURISTIC ALGORITHM}

Jabr has shown [20] that the transformer design problem can be solved accurately by geometric programming (GP). The use of this branch of non-linear mathematical optimisation has two main advantages: guarantees that the obtained solution is the global minimum and it can be solved efficiently by the novel interior-point method based algorithms [1,26-28]. To formulate a problem in GP format, the equality constraints shall be formulated in monomial form, and the inequalities in a special posynomial form [26]. The previous articles of the authors $[24,25]$ have shown that the short circuit impedance cannot be formulated in either monomial nor in posynomial format properly. A solution for the problem has be shown by the combination of this method with a branch and bound search [25]. The BB executes a binary search in sense that the solution space is divided into several subspaces, which can be described in appropriate convex terms [25]. The BB can produce large number of sub-cases, but the $\mathrm{BB}$ is usually quite efficient in the practice because it employs advanced techniques to remove certain parts of the search tree before evaluation. This meta-heuristic approach provides a solution which is close to the global optima rapidly.

\section{OPTIMISATION MODEL OVERVIEW}

The following subsections give a short overview from the model. It discretizes the used model variables (Table 1), the used object function and the constraints, which determines the physical properties of the transformer.

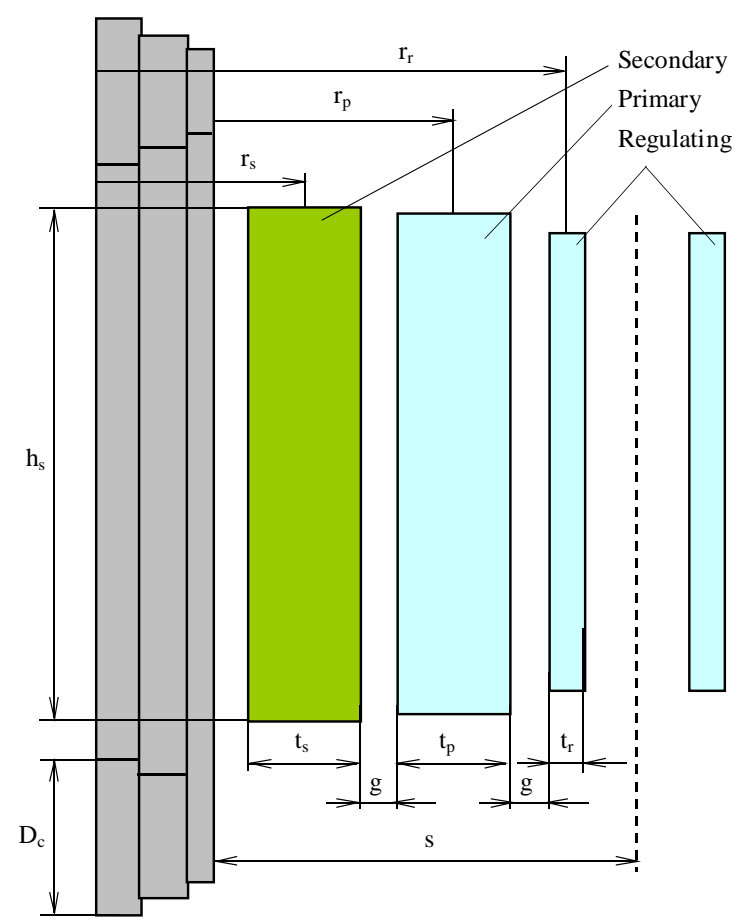

Fig. 1. Design variables in a working window of a core-form transformer's active part

\subsection{Objective Function}

The objective of this optimisation model is to reduce the total cost of ownership (TCO), which involves the product price $(P P)$ and the capitalised cost of the losses. The $T C O$ is defined by

$$
T C O=P P+K_{1} P_{\mathrm{nll}}+K_{2} P_{\mathrm{ll}},
$$

where $P_{\text {nll }}$ and $P_{11}$ represent the no-load and the load losses. These are design variables, which are summarised in Table $1 . K_{1}$ and $K_{2}$ are the capitalisation factors of no-load and load loss, respectively, in EURO/kW. As discussed in the Introduction, to obtain the exact value of $P P$ is the result of a complex transformer design process. 
Therefore, this optimisation process takes the transformer active part into consideration according to the literature, because the dimensions of this part determine the overall dimensions of the transformer. In this paper the term "active part" means the sum of the core and the windings. So the $P P$ is approximated by $f_{0}$ as follows:

$$
P P \simeq f_{0}=\sum_{k=0}^{n} C_{k} M_{k}
$$

where $C_{k}$ is the specific cost of the $k^{\text {th }}$ material of the transformer's active part in EURO $/ \mathrm{kg}$, and $M_{k}$ is the mass of the $k^{\text {th }}$ material in $\mathrm{kg}$. In this model $k=$ $0,1,2,3$ represents the transformer's core, the primary winding, the secondary winding and the regulating winding. The investigated working window arrangement, and the schematic view of the geometrical design variables is shown in Fig. 1.

\subsection{Active Part Model}

The active part model's performance parameters are determined by the equality and inequality constraints. These transformer performance parameters are included in the nameplate data [20], [20]. The variables of the optimisation model are summarised in Table 1.

Several types of windings and winding materials can be applied in a core-form power transformer winding system, (eg disc, layer, helical) and to select the best suitable solution, the designer must consider many requirements (eg lightning impulse test), which are considered in the tendering design stage only approximately. Therefore, instead of handling the different types of winding systems, this model takes the windings into consideration with their copper filling factor, which is defined by the ratio of the winding cross section and the sum of the copper cross section. This is a widely used technique in the industry $[1-3,18,20]$, gives reasonable results for the copper masses and the load losses. This factor is estimated accurately, from the manufacturer's database from similar, manufactured windings (voltage, power, insulation class and the type of the winding). From the windings' copper mass, the DC losses are easily calculated. The precise calculation of stray losses needs advanced numerical or analytical methods [1-3]. In the optimisation algorithm, an analytical formula is used to estimate the optimal eddy losses in the windings and an empirical factor is used to take into consideration the other stray losses, which are generated in the structural components.

The core mass is calculated from the core geometry, which is determined by the core diameter, the turn voltage, the geometry of the working window (Fig. 1) and the type of the core. In this paper a three-phase, three-legged core is examined. There are many advanced techniques described in the literature for core loss calculation [13$16,31]$. Because of the GP modelling restrictions, the noload loss is calculated by a simple multiplication of the core mass and the power loss $[\mathrm{W} / \mathrm{kg}]$. The power loss is a fitted function to the manufacturer given loss curve of the chosen electrical steel [32].

As previously mentioned, in the case of shell type transformers the usability of the GP is not problematic because a prescription for the short circuit impedance (SCI) can be written in the desired monomial form. However, in the case of core-form transformers, this cannot be done. Moreover, the critical lower bound cannot be formulated in the required polynomial form. Therefore, the SCI is calculated via the branch and bound search by some abstract variables which represent the parts of the SCI formula (Table 1). The method of branch and bound search is used to execute a binary search in this subspace. The [33] describes the meta-heuristic method in more detail.

The tank dimensions are calculated from the outer dimensions of the active part and the insulation structure (Fig. 2). Limiting the outer dimensions has high importance, because the transportation cost increases nonlinearly and plays an important role in the transformer installation cost.
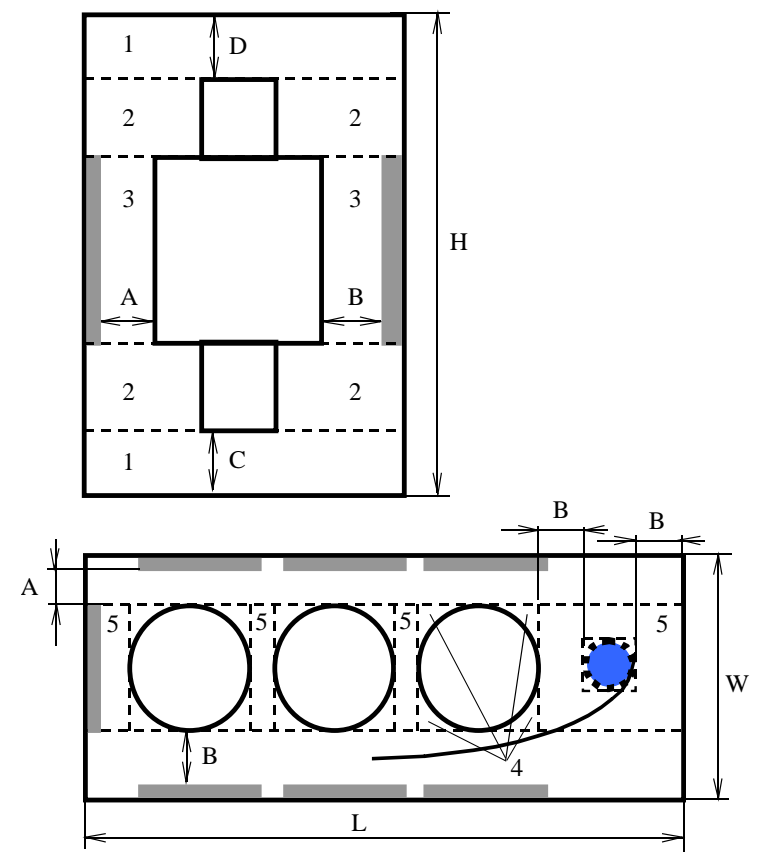

Fig. 2. The insulation structure of the examined transformer. The applied insulation distances are denoted by label A and B. The numbers indicates the different sections which used for the oil volume calculation.

\subsection{Extension of the Transformer Model with the Cost of the Oil}

Firstly, the objective function is extended with the cost of the insulating oil and the cost of the radiators:

$$
f_{0}^{\prime}=f_{0}+C_{\text {oil }} V_{\text {oil }}+C_{\text {rad }} t_{\mathrm{rad}}
$$

where $C_{\text {oil }}$ and $C_{\text {rad }}$ represent the cost of the oil and the radiators, respectively in $\mathrm{EURO} / \mathrm{m}^{3}$ and in $\mathrm{EURO} /$ piece dimensions. 


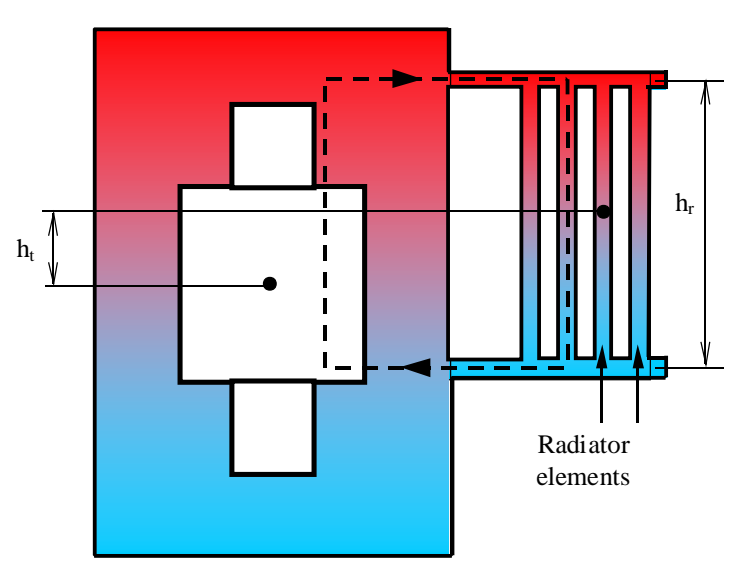

Fig. 3. Schematic view from a radiator type, natural oil flow type cooling. The diagram shows the new GP model variables $\left(h_{t}\right.$ and

$h_{r}$ ) which are introduced in the extended transformer model.

The transformer oil is contained by not only the transformer's tank, but also within the conservator and the cooling equipment. For the sake of simplicity this model expects an xxAN type $[34,35]$ outer cooling system, where the generated heat is dissipated by radiators (see Fig. 3). This can be defined by

$$
V_{\mathrm{oil}}=V_{\mathrm{To}}+V_{\mathrm{Co}}+V_{\mathrm{Ro}},
$$

where $V_{\text {To }}, V_{\text {Co }}$ and $V_{\text {Ro }}$ mean the oil volume in the tank, conservator and cooling system of the transformer, respectively in $\mathrm{m}^{3}$.

The volume of the oil in the transformer's tank $\left(V_{\text {To }}\right)$ is generally determined by

$$
V_{\mathrm{oil}}=L W H-V_{\mathrm{ap}},
$$

where the first part of the equation is the inner volume of the transformer's tank, the second part of the equation represents the volume of the active part elements. This volume can be calculated from the variables of the core and the windings (Table 1), but the subtraction is not permitted by the rules of the geometrical modelling $[26,27]$. Hence the inner region of the transformer is modelled by the sum of the different sections, see in Fig. 2. Therefore, the sum of these sections approximates the mass of the oil contained by the tank. The volumes of these different sections can be expressed as

$$
V_{\mathrm{oil1}}=(D+C) L W
$$

where $D$ is the distance between the core and the cover in $[\mathrm{mm}]$, the $C$ is the distance between the core and the plate in [mm]. These distances are illustrated in Fig. 2. $L$ and $W$ are the length and width variables of the previous model (Table 1).

$$
V_{\mathrm{oil} 2}=\left(2 D_{\mathrm{C}}+E\right)\left(2 s+A+B+2 \delta_{M S}\right) L,
$$

where $D_{\mathrm{C}}$ is the diameter of the transformer's core and the yokes in this case, $s$ denotes the width of the working window, so it is also a design variable (Table 1 ). $E$ represents the sum of the end insulation in $\mathrm{mm}$. $A$ and $B$ are the insulation distances in the transformer tank, see in Fig. 2, in mm. $\delta_{M S}$ is the width of the flux shunt in $(\mathrm{m})$, if it is applicated.

$$
\begin{gathered}
V_{\mathrm{oil} 3}=(A+B) h_{\mathrm{s}} L, \\
V_{\mathrm{oil} 4}=m((1-\pi / 4) s)^{2} h_{\mathrm{s}},
\end{gathered}
$$

where $m$ is the number of wound limbs.

$$
V_{\mathrm{oil} 5}=h_{\mathrm{s}} s\left(A+2 B+2 g+(1-\pi / 4) D_{\mathrm{OLTC}}\right),
$$

where $g$ is the phase insulation in $(\mathrm{mm})$, and $D_{\text {OLTC }}$ is the contact circle diameter in $(\mathrm{mm})$. Therefore, the oil contained by the transformer's tank is defined by

$$
V_{\mathrm{To}}=V_{\mathrm{oil} 1}+V_{\mathrm{oil} 2}+V_{\mathrm{oil} 3}+V_{\mathrm{oil} 14}+V_{\mathrm{oil} 15},
$$

The exact calculation of the conservator volume is a difficult task in this preliminary design stage. However, the amount of the conserved oil is approximated well by the widely used method, which uses a simple constant for the estimation. The selection of this constant $\left(c_{\mathrm{emp}}\right)$ depends on a manufacturer's statistical analysis. Therefore, the calculation of the oil mass is described by

$$
V_{\mathrm{Co}}=c_{\mathrm{emp}} V_{\mathrm{To}},
$$

The oil contained by the radiators can be calculated very easily, if the height of the radiators $\left(h_{\mathrm{r}}\right)$, and the total number of the radiator elements $(t)$ are known by

$$
V_{\mathrm{Ro}}=c_{\mathrm{rad}} t h_{\mathrm{r}} A_{\mathrm{r}},
$$

where $A_{\mathrm{r}}$ is the area of the radiator element in $\left(\mathrm{mm}^{2}\right)$, and $c_{\text {rad }}$ is a constant which describes the contained oil in a single element with the given parameters. In the presented optimisation model a DIN50216-6 type radiator is used, therefore the radiator width is $520 \mathrm{~mm}$ and the radiator thickness is $45 \mathrm{~mm}$.

\subsection{Extension of the Transformer Model with the Cooling Considerations}

The basis of the oil volume determination in the radiator banks is to obtain the sufficient number of radiator elements. Therefore, the GP model is extended by a method, which is capable of calculating the outer cooling. The total amount of the generated losses $\left(P_{t}\right)$ are passed through to the surface of the tank or the radiators to the air. This heat dissipation from the tank occurs by means of radiation and natural convection, which must be higher or equal than the worst case of the generated losses. Accordingly, this can be written to the following form:

$$
\begin{gathered}
P_{\text {nll }}+r P_{\text {ll }} \leq P_{\mathrm{t}}, \\
P_{\mathrm{t}} \leq P_{\text {rad }}+P_{\text {et }}+P_{\mathrm{s}},
\end{gathered}
$$


Table 2. List of the optimisation model input parameters

\begin{tabular}{|c|c|c|c|}
\hline \multicolumn{2}{|r|}{ Parameter } & Dimension & Value \\
\hline \multicolumn{2}{|c|}{ Nominal power } & MVA & 50 \\
\hline \multicolumn{2}{|l|}{ Frequency } & $\mathrm{Hz}$ & 50 \\
\hline \multicolumn{2}{|c|}{ Connection group } & & YNd11 \\
\hline \multicolumn{2}{|c|}{ Number of phases } & $\#$ & 3 \\
\hline \multicolumn{2}{|c|}{ Short circuit impedance } & $\%$ & 12 \\
\hline \multicolumn{2}{|c|}{ Main gap } & $\mathrm{mm}$ & 97 \\
\hline \multicolumn{2}{|c|}{ Sum of the end insulation } & $\mathrm{mm}$ & 150 \\
\hline \multicolumn{2}{|c|}{ LV side distance } & $\mathrm{mm}$ & 100 \\
\hline \multicolumn{2}{|c|}{$\mathrm{HV}$ side distance } & $\mathrm{mm}$ & 220 \\
\hline \multicolumn{2}{|c|}{ Phase distance } & $\mathrm{mm}$ & 37 \\
\hline \multicolumn{2}{|c|}{ Core-Inner winding distance } & $\mathrm{mm}$ & 20 \\
\hline \multicolumn{2}{|c|}{ Tertiary clearance } & $\mathrm{mm}$ & 66 \\
\hline \multicolumn{2}{|c|}{ Core-Tank insulation top } & $\mathrm{mm}$ & 50 \\
\hline \multicolumn{2}{|c|}{ Core-Tank insulation bottom } & $\mathrm{mm}$ & 40 \\
\hline \multicolumn{2}{|c|}{ Maximum winding heating above oil } & $\mathrm{K}$ & 65 \\
\hline \multicolumn{2}{|c|}{ Insulating oil price } & EURO/l & 1.2 \\
\hline \multicolumn{2}{|c|}{ Radiator price } & EURO & 23 \\
\hline \multirow{5}{*}{ Core } & Number of legs & \# & 3 \\
\hline & Flux density limit in columns & $\mathrm{T}$ & 1.7 \\
\hline & Filling Factor & $\%$ & 90 \\
\hline & Material Type & & $\mathrm{M} 1 \mathrm{H}$ \\
\hline & Material Price & $\mathrm{EURO} / \mathrm{kg}$ & 3.5 \\
\hline \multirow{6}{*}{$\begin{array}{l}\text { Low Voltage } \\
\text { Winding }\end{array}$} & Line Voltage & $\mathrm{kV}$ & 20 \\
\hline & Phase Voltage & $\mathrm{kV}$ & 20 \\
\hline & BIL & $\mathrm{kV}$ & 125 \\
\hline & $\mathrm{AC}$ & $\mathrm{kV}$ & 50 \\
\hline & Copper filling factor & $\%$ & 70 \\
\hline & Material and manufacturing price & $\mathrm{EURO} / \mathrm{kg}$ & 12 \\
\hline \multirow{6}{*}{$\begin{array}{l}\text { High Voltage } \\
\text { Winding }\end{array}$} & Line Voltage & $\mathrm{kV}$ & 120 \\
\hline & Phase Voltage & $\mathrm{kV}$ & 69.36 \\
\hline & BIL & $\mathrm{kV}$ & 550 \\
\hline & $\mathrm{AC}$ & $\mathrm{kV}$ & 230 \\
\hline & Copper filling factor & $\%$ & 60 \\
\hline & Material and manufacturing price & $\mathrm{EURO} / \mathrm{kg}$ & 10 \\
\hline \multirow{4}{*}{$\begin{array}{l}\text { Regulating } \\
\text { Winding }\end{array}$} & Regulating range & $\%$ & \pm 10 \\
\hline & Insulation & & Fully insulated \\
\hline & Regulated winding & & High voltage \\
\hline & Filling factor & $\%$ & 60 \\
\hline
\end{tabular}

where $r$ is a factor, represents the extra losses in the negative tapping position. $P_{\text {rad }}$ and $P_{\text {et }}$ represents the heat dissipated in the radiator bank and through the tank by convection in $\mathrm{kW}, P_{\mathrm{s}}$ represents the radiation heat loss in $\mathrm{kW}$.

The expression (15) is unattainable in a GP problem because it is not posynomial. This means that should it be used as a constraint function in the GP model as it is shown for the SCI [25]. Therefore, the GP model is extended by three new abstract values, which divide this formula to three convex subspaces, which can be described in appropriate posynomial terms. The method of branch-and-bound is applied to consider (15) similarly to the SCI [25].

\subsection{Radiator Heat Dissipation Model}

The transformer optimisation model is extended by an a priory empirical radiator heat dissipation model. In this model the radiator heat loss area $\left(A_{\mathrm{r}}\right)$ is given by a linear function of the radiator height $\left(h_{\mathrm{r}}\right)$. The $\left(c_{\mathrm{r}}\right)$ constant is calculated by the radiator manufacturer's data-sheet [32]:

$$
\begin{gathered}
P_{\mathrm{r}}=A_{\mathrm{r}} p_{\text {ea }} \prod_{k=1}^{4} c_{k}, \\
A_{\mathrm{r}}=c_{\mathrm{r}} h_{\mathrm{r}} t,
\end{gathered}
$$

where $h_{\mathrm{r}}$ and $t$ are the new variables in the GP model (Table 1), $p_{\text {ea }}=0.28 \mathrm{~kW} / \mathrm{m}^{2}$ is the surface heat transfer coefficient, and the $c_{k}$ constants take the differences between the different radiator layouts into consideration in an a priory empirical way. The main advantage of eq. (17) is that it can be added to the GP equation system as a monomial constraint without any GP modelling difficulties.

\subsection{Tank Heat Dissipation Model}

The transformer tank heat is dissipated by convection $\left(P_{\text {et }}\right)$ and by radiation $\left(P_{\mathrm{s}}\right)[1-3,21,36]$. These effects 
Table 3. List of the optimisation model results

\begin{tabular}{|c|c|c|c|c|c|}
\hline & & A1 & $\mathrm{A} 2$ & B1 & $\mathrm{B} 2$ \\
\hline$\overline{k_{1}}$ & $\mathrm{EURO} / \mathrm{kW}$ & 7066 & 7066 & 7066 & 7066 \\
\hline$\underline{k_{2}}$ & $\mathrm{EURO} / \mathrm{kW}$ & 926 & 926 & 6825 & 6825 \\
\hline \multicolumn{6}{|l|}{ CORE DATA } \\
\hline core diameter & $\mathrm{mm}$ & 670 & 640 & 826 & 820 \\
\hline flux density & $\mathrm{T}$ & 1.5 & 1.58 & 1.52 & 1.54 \\
\hline core mass & $\mathrm{t}$ & 24.1 & 22.2 & 43.9 & 43.7 \\
\hline core loss & $\mathrm{kW}$ & 17.8 & 18.9 & 33.7 & 34.3 \\
\hline turn voltage & $\mathrm{V}$ & 105.7 & 101.6 & 162.7 & 162.5 \\
\hline \multicolumn{6}{|l|}{ INNER WINDING } \\
\hline inner diameter & $\mathrm{mm}$ & 775 & 748 & 992 & 988 \\
\hline winding height & $\mathrm{mm}$ & 1120 & 1200 & 1000 & 1000 \\
\hline winding width & $\mathrm{mm}$ & 65 & 67.5 & 127 & 127,5 \\
\hline turn number & $\#$ & 189 & 197 & 123 & 123 \\
\hline current density & $\mathrm{A} / \mathrm{mm} 2$ & 3.1 & 2.9 & 1.15 & 1.185 \\
\hline \multicolumn{6}{|l|}{ OUTER WINDING } \\
\hline inner diameter & $\mathrm{mm}$ & 1004 & 980 & 1400 & 1394 \\
\hline winding height & $\mathrm{mm}$ & 1064 & 1140 & 950 & 950 \\
\hline winding width & $\mathrm{mm}$ & 91 & 92 & 205 & 206 \\
\hline turn number & & 656 & 683 & 426 & 427 \\
\hline current density & $\mathrm{A} / \mathrm{mm} 2$ & 2.6 & 2.5 & 0.835 & 0.905 \\
\hline \multicolumn{6}{|l|}{ REGULATING } \\
\hline inner diameter & $\mathrm{mm}$ & 1180 & 1158 & 1700 & 1688 \\
\hline winding height & $\mathrm{mm}$ & 896 & 960 & 800 & 800 \\
\hline winding width & $\mathrm{mm}$ & 11 & 11.5 & 21 & 17.5 \\
\hline current density & $\mathrm{A} / \mathrm{mm} 2$ & 2.6 & 2.5 & 1. & 1. \\
\hline load loss & $\mathrm{kW}$ & 196 & 188.6 & 61.5 & 61.3 \\
\hline oil volume & $\mathrm{m} 3$ & 16.0 & 15.7 & 25.75 & 25.5 \\
\hline radiator $\mathrm{nr}$ & $\#$ & 306 & 296 & 117 & 118 \\
\hline tank heat loss & $\mathrm{kW}$ & 10.8 & 10.75 & 15.4 & 15.1 \\
\hline main gap & $\mathrm{mm}$ & 37 & 37 & 37 & 37 \\
\hline copper mass & $\mathrm{kg}$ & 8419 & 8946 & 21821 & 21756 \\
\hline objective function without oil & EURO & 488156 & 492917 & 1054090 & 1054236 \\
\hline objective function with oil & EURO & 514700 & 514628 & 1087681 & 1087550 \\
\hline
\end{tabular}

are considered by two similar empirical formulas which can be easily added to the GP model as a posynomial constraint.

$$
\begin{gathered}
P_{\mathrm{et}}=A_{\mathrm{f}} p_{\mathrm{ea}} c_{\mathrm{f}}+A_{\mathrm{ep}} p_{\mathrm{ea}} c_{\mathrm{ep}}, \\
P_{\mathrm{s}}=A_{\mathrm{s}} p_{\mathrm{sa}} c_{\mathrm{f}}+A_{\mathrm{sp}} p_{\mathrm{sa}} c_{\mathrm{ep}},
\end{gathered}
$$

where $p_{\text {ea }}=0.28 \mathrm{~kW} / \mathrm{m}^{2}$ and $p_{\text {sa }}=0.28 \mathrm{~kW} / \mathrm{m}^{2}$ are the surface heat transfer coefficients. The $c_{\mathrm{f}}$ and $c_{\mathrm{ep}}$ constants are selected by a measurement, the difference between them is that $c_{\mathrm{f}}$ is dependent on the top-oil temperature and $c_{\mathrm{ep}}$ is the function of the average oil temperature. $A_{\mathrm{f}}$ means the cover surface of the tank and $A_{\mathrm{ep}}$ is the are of the side surface. They can be easily calculated by the model variables (Table 1 ). The radiation surfaces are calculated similarly but to the periphery of the transformer, which is also a function of the radiator elements.

\section{RESULTS AND DISCUSSION}

\subsection{Test Transformer Physical Parameters}

The extended optimisation method has been tested on a three-phase, 50 MVA power transformer. The datasheet with all of the selected input parameters is presented in Table 2.

For the sake of simplicity, the transformer cooling arrangement was chosen as ONAN and the ambient temperature was specified $40^{\circ} \mathrm{C}$. Because of this, the upper limit of the winding current density was set to $3 \mathrm{~A} / \mathrm{mm}^{2}$ in the main windings and $3.5 \mathrm{~A} / \mathrm{mm}^{2}$ in the regulating winding. The maximum winding gradient was considered $15 \mathrm{~K}$. The allowed winding oil temperature rise was defined to $\Theta_{\text {wo }}=65 \mathrm{~K}$, according to the IEC-60076 standard [34]. Therefore, the allowable average oil temperature rise was $\Theta_{\mathrm{ao}}=47 \mathrm{~K}$ with a $3 \mathrm{~K}$ margin, and the maximum oil temperature rise was $\Theta_{\mathrm{om}}=61.6 \mathrm{~K}$.

The applied core material in the optimisation was a TRAN-COR H1 grade electrical steel [32]. The maximum of the flux density was limited to $1.7 \mathrm{~T}$ considering the saturation. 
The insulation distances were chosen by a priory empirical rules $[1-3,36]$. These methods were based on the lightning impulse test and AC test prescriptions. The copper filling factors were approximated by statistical data, which were based on the manufacturing experience.

\subsection{Discussion of the Results}

Table 3 summarises the optimal design variables in the four examined cases. Firstly, we can compare the objective functions in the two sub-scenarios. In both scenarios, the values of the objective function considering the cost of the cooling are equal in the two sub-scenarios.

In scenario A, there is no significant difference between the value of the objective functions. The difference between the object function of the two sub-cases (A1 and A2) is relatively small (app. 1\%), in contrast to the optimal set of design values where the differences are significant. The shape of the transformer's working window is different in the two sub-cases. As a result of the cooling considerations the working window is higher and slimmer in the (A2) sub-scenario, which leads to a higher thermal head with more effective oil-flow. As shown in Table 3, the core diameter is less in sub-case (A2), hence the cooling consideration causes $4 \%$ growth in the turn voltage. This results the decrease of the core-copper ratio. The mass of the transformer's core decreases by $10 \%$ and the increase in the total mass of the copper is $6 \%$ in the windings.

Similarly, there is no significant difference between the values of the objective function with oil in the case of scenario B. Furthermore, there is no significant difference between the set of optimal design variables. Therefore, taking the cooling cost into consideration has no significant influence on the transformer design in this case. The current densities and electrical losses are very small because of the high capitalisation cost of the load loss. Because of the ratio of $k_{1}$ and $k_{2}$, the ratio of the load and no-load losses are close to $1: 1$. The diameter of the transformer's core is very large because of the high capitalisation cost of the no-load loss. This large core diameter determines a high turn voltage, which indicates a low core mass/copper mass ratio in the active part. The large core radius leads to an increased buckling stress in the inner winding and resulting in the optimal solution being inappropriate.

\section{CONCLUSION}

The key parameters of transformer design are determined by the overall cost, which contains the cost of the materials, the labour and the capitalisation costs. This minimisation is a non-linear problem and several optimisation methods were introduced to solve this problem. However, most of the previous studies did not take the cost of the insulation oil and the outer cooling equipment (e.g. radiators and ) into account, they consider only the major cost components and constraints of the active part. In the case of the core-form power transformers none of these solutions consider the cost of the insulation and the cooling equipment. This paper has shown a solution for this problem, with the extension of an efficient geometric programming based, meta-heuristic algorithm. With this algorithm, the effect of the insulation oil cost is examined in the optimal design. The paper shows if the cost of the capitalisation losses are high, the consideration of the cooling has no significant effect on the optimal set of variables. However, in the other case, when the load loss is relatively high, there are significant differences in the optimal design variables. The results show that if the insulating oil is considered, the optimal value of the turn voltage is increased, therefore the ratio of the core and the copper is decreased. Moreover, the consideration of cooling results in a slimmer design, which is favoured by designers because of the higher thermal head and the better short circuit withstand properties. However, the difference between the total owning costs are not significant. The proposed method can be readily used in practice for design of ONAN/ONAF transformers.

\section{Acknowledgement}

The authors would like to acknowledge the valuable comments and suggestions of David Smith, Péter Hugli, Zoltán Bankó and Zsolt Szőke .

\section{REFERENCES}

[1] Del VECCHIO, R. M.-POULIN, B.-FEGHALI, P. T.SHAH, D. M.-AHUJA, R.: Transformer Design Principles: with Applications to Core-Form Power Transformers, CRC press, 2010.

[2] RYAN, H. M. : High Voltage Engineering and Testing 3rd Edition. IET, 2013, N0 32

[3] KULKARNI, S. V.-KHAPARDE, S. : Transformer Engineering: Design and Practice. CRC Press, 2004,, vol. 25.

[4] KAPP, G. : Transformatoren für Wechselstrom und Drehstrom (Transformers for Single and Multiphase Currents: A Treatise on Their Theory, Construction, and Use), Nabu Press, Charleston SC, United States, 2012.

[5] ÚJHÁZY, G. : Erőátviteli transzformátorok gépi számításának kérdései (Application of Computers for Power Transformer Design), PhD dissertation, Budapest University of Technology and Economics, 1969. (In Hungarian)

[6] JESZENSZKY, S. : History of Transformers, Power Engineering Review, IEEE 16 No. 12 (1996), 9.

[7] IEEE Loss Evaluation Guide for Power Transformers and Reactors, IEEE IEEE Std C57 120, 1992.

[8] GEORGILAKIS, P. S. : Environmental Cost of Distribution Transformer Losses, Applied Energy 88 No. 9 (2011), 3146-3155.

[9] CORHODZIC, S.-KALAM, A.: Assessment of Distribution Transformers using Loss Capitalization Formulae, Journal of Electrical and Electronics Engineering Australia 20 No. 1 (2000), 43-48.

10] GEORGILAKIS, P.-AMOIRALIS, E. : Distribution Transformer Cost Evaluation Methodology Incorporating Environmental Cost, IET Generation, Transmission \& Distribution 4 No. 7 (2010), 861-872.

11] CHOWDhury, A.-BERTLinG, L.-CUSTER, D. : Determining Distribution Substation Transformer Optimal Loadings using a Reliability Cost-Benefit Approach, in International Conference on Probabilistic Methods Applied to Power Systems PMAPS 2006, IEEE, 2006, pp. 1-9. 
[12] OROSZ, T.-SŐRÉS, P.-RAISZ, D.-TAMUS, Á. Z. : Analysis of the Green Power Transition on Optimal Power Transformer Designs, Periodica Polytechnica Electrical Engineering and Computer Science 59 No. 3 (2015), 125-131.

[13] AMOIRALIS, E. I.-TSILI, M. A.-KLADAS, A. G. : Transformer Design and Optimization: a Literature Survey, Power Delivery, IEEE Transactions on 24 No. 4 (2009), 1999-2024.

[14] KHATRI, A.-MALIK, H.-RAHI, O.: Optimal Design of Power Transformer using Genetic Algorithm, in Communication Systems and Network Technologies (CSNT), 2012 International Conference on, IEEE, 2012, pp. 830-833.

[15] OLIVARES-GALVAN, J.-GEORGILAKIS, P.-FOFANA, I.-MAGDALENO-ADAME, S.-CAMPERO-LITTLEWOOD, E.-ESPARZA-GONZALEZ, M.: A Bibliographic Analysis of Transformer Literature 2001-2010.

[16] AMOIRALIS, E. I.-TSILI, M. A.-GEORGILAKIS, P. S. : The State of the Art in Engineering Methods for Transformer Design and Optimization: a Survey, Journal of Optoelectronics and Advanced Materials 10 No. 5 (2008), 1149.

[17] ABetti, P.-CUthbertson, W.-Williams, S. : Philosophy of Applying Digital Computers to the Design of Electric Apparatus, Transactions of the American Institute of Electrical Engineers, Part I: Communication and Electronics 77 No. 3 (1958), 367-379.

[18] ANDERSEN, O. W.: Optimized Design of Electric Power Equipment, Computer Applications in Power, IEEE 4 No. 1 (1991), 11-15.

[19] YADAV, A. K.-SINGH, A.-MALIK, H.-AZEEM, A. : Cost Analysis of Transformers Main Material Weight with Artificial Neural Network (ann), in Communication Systems and Network Technologies (CSNT), 2011 International Conference on, IEEE, 2011, pp. 184-187.

[20] JABR, R. A.: Application of Geometric Programming to Transformer Design, Magnetics, IEEE Transactions on $\mathbf{4 1}$ No. 11 (2005), 4261-4269.

[21] GEORGILAKIS, P. S. : Spotlight on Modern Transformer Design, Springer Science \& Business Media, 2009.

[22] AMOIRALIS, E. I.-TSILI, M. A.-GEORGILAKIS, P. S.KLADAS, A. G.-SOUFLARIS, A. T. : A Parallel Mixed Integer Programming-Finite Element Method Technique for Global Design Optimization of Power Transformers, IEEE Transactions on Magnetics 44 No. 6, 1022-1025 2008.

[23] TSIVGOULI, A. J.-TSILI, M. A.-KLADAS, A. G.-GEORGILAKIS, P. S.-SOUFLARIS, A. T.-SKARLATINI, A. D. : Geometry Optimization of Electric Shielding in Power Transformers based on Finite Element Method, Journal of Materials Processing Technology 181 No. 1 (2007), 159-164.

[24] OROSZ, T.-SLEISZ, A.-VAJDA, I. : Core-Form Transformer Design Optimization with Branch and Bound Search and Geometric Programming, in Power and Electrical Engineering of Riga Technical University (RTUCON), 2014 55th International Scientific Conference on, IEEE, 2014, pp. 17-21.
[25] OROSZ, T.-SLEISZ, Á.-TAMUS, Z.: Meta-Heuristic Optimization Preliminary Design Process of Core-Form Autotransformers, IEEE Transaction on Magnetics 99 (2016).

[26] BOYD, S.-VANDENBERGHE, L.: Convex Optimization, Cambridge University Press, 2004

27] BOYD, S.-KIM, S.-J.-VANDENBERGHE, L.-HASSIBI, A. : A Tutorial on Geometric Programming, Optimization and Engineering 8 No. 1 (2007), 67-127.

28] ANDERSEN, M. S.-DAHL, J.-VANDENBERGHE, L. : CVXOPT: A Python Package for Convex Optimization, version 1.1.6, Available at cvxopt.org, 2013.

29] RYDER, S.-VAUGHAN, I. J. et al : A Simple Method for Calculating Core Temperature Rise in Power Transformers, Power Delivery, IEEE Transactions on 19 No. 2 (2004), 637-642.

[30] GURU, B. S.-HIZIROGLU, H. R.: Electric Machinery and Transformers, vol. 726, Oxford University Press, New York, 2001.

31] KUCZMANN, M.: Using the NewtonRaphson Method in the Polarization Technique to Solve Nonlinear Static Magnetic Field Problems, Magnetics, IEEE Transactions on 46 No. 3 (2010), 875-879.

32] AK-Steel, TRAN-COR H Grain Oriented Electrical Steels, June 2013.

[33] GROSSMAnN, I. E. : Review of Nonlinear Mixed-Integer and Disjunctive Programming Techniques, Optimization and Engineering 3 No. 3 (2002), 227-252.

[34] IEC Standard Power Transformers-Temperature Rise, Std. IEC Std 60 076-2, 1993.

35] EEE Standard General Requirements for Liquid-Immersed Distribution, Power, and Regulating Transformers, Std. IEEE Std. C57.12.00-2000, 2000.

[36] KARSAI, K.-KERÉNYI, D.-KISS, L. : Large Power Transformers, Elsevier Science Pub. Co. Inc., New York, 1987.

Received 18 July 2016

Tamás Orosz has received his MSc degree in Electrical Engineering from Budapest University of Technology and Economics (BUTE), Budapest, Hungary in 2012. He is currently working as a software developer at Bosch Electric Drives division at Budapest, and as a $\mathrm{PhD}$ student in Department of Electric Power Engineering in BUTE, Hungary. His fields of research include power transformer optimization, numerical calculations of different parameters for power transformers.

Zoltán Ádám Tamus received his $\mathrm{PhD}$ degree from Budapest University of Technology and Economics, Budapest, Hungary in 2011 and works as an associate professor in Department of Electric Power Engineering in the same university. His fields of research include electrical insulation technology, insulation diagnostics, health effects of electromagnetic fields and fundamentals of electrical engineering. 